\title{
Trends and Clinical Outcomes in Young-onset Colorectal Cancer Patients
}

\author{
Serene SN $\underline{\text { Goh }},{ }^{1}$ MBBS, MRCS, MMED, Edith XL Loo, ${ }^{2}$ MBBS, Daniel JK Lee, ${ }^{1}$ MRCS, MMED, FRCS
}

\begin{abstract}
Introduction: Young individuals with colorectal cancer (CRC) tend to be diagnosed at advanced stages and are not routinely included in screening programmes. This study describes the incidence, disease pattern and factors affecting overall survival in youngonset CRC.
\end{abstract}

Methods: A retrospective study of young-onset CRC patients diagnosed between 2010 and 2017 in a tertiary hospital was conducted.

Results: There were 99 patients, $69.7 \%$ had left-sided while $30.3 \%$ had right-sided CRC. The mean age was 43.3 years $(43.3 \pm 5.0)$ and 62 patients $(62.6 \%)$ were male. The incidence of young-onset CRC has been on the rise since 2014. Out of 99 patients, 65 $(65.7 \%)$ underwent elective surgery, $30(30.3 \%)$ underwent emergency surgery and the remainder $5(4.0 \%)$ were palliated. The most common presenting complaints for patients who underwent elective surgery were abdominal pain, per-rectal bleeding and altered bowel habits. For patients who required emergency surgery, $20(66.6 \%)$ presented with intestinal obstruction and $10(33.3 \%)$ had intestinal perforation. There were $42(42.4 \%)$ stage III CRC and $20(20.2 \%)$ stage IV CRC. The most frequent metastatic site was the liver $(20 / 20,100 \%)$. Five patients had signet ring cells $(5.1 \%)$ in their histology while $15(15.2 \%)$ had mucinous features. The overall 5-year survival of young-onset CRC was $82.0 \%$. Advanced overall stage (hazard ratio (HR) 6.1, CI 1.03-3.62) and signet ring histology (HR 34.2, CI 2.24-5.23) were associated with poor prognosis.

Conclusion: Young-onset $\mathrm{CRC}$ tend to be left-sided with advanced presentations. However, their 5-year survival remains favourable as compared to the general population.

Ann Acad Med Singap 2020;49:848-56

Keywords: Colorectal screening in the young, early-onset colorectal cancer, signet ring cell colorectal cancer

\section{Introduction}

The overall trend of colorectal cancer in individuals above the age of 50 is decreasing worldwide. ${ }^{1}$ This has been attributed to the international adoption of screening programmes including faecal occult blood testing and colonoscopy. ${ }^{2}$ However, the rising incidence of nonhereditary colorectal cancer (CRC) in individuals younger than 50 years old in high income countries has become concerning. Studies have shown that younger individuals with red flag symptoms of colorectal cancer are usually diagnosed later than their older counterparts..$^{3-5}$ Early cancer stage at diagnosis has been found to be associated with better prognosis and reduced mortality from CRC. ${ }^{6,7}$ However, young individuals below the age of 50 are not routinely included in these programmes. Besides diagnostic delays, young individuals with CRC may differ from their older counterparts in terms of tumour biology and clinical outcomes. ${ }^{8,9}$ Hitherto, there has been no studies on young-onset colorectal cancer in Singapore. This study aims to describe the incidence, disease pattern and factors affecting overall survival in young-onset CRC in our institution.

\footnotetext{
${ }^{1}$ Department of Surgery, Khoo Teck Puat Hospital, Singapore

${ }^{2}$ Lee Kong Chian School of Medicine, Nanyang Technological University, Singapore

Address for Correspondence: Dr_Serene Goh Si Ning, Department of Surgery, Khoo Teck Puat Hospital, 90 Yishun Central, Singapore 768828

Email: serene.goh@mohh.com.sg
} 


\section{Methods}

\section{Study cohort}

A retrospective cohort study of patients with young-onset CRC was conducted in a tertiary hospital in Singapore, during the period of 2010 to 2017. Young-onset CRC patients was defined as patients who were under the age of 50 years old at the time of diagnosis. Patients with sporadic colorectal adenocarcinomas were included. Exclusion criteria were patients with hereditary colorectal cancers, inflammatory bowel disease, concurrent noncolonic cancers, and patients under 18 years of age, as they were managed in paediatric hospitals. The primary objective is to describe the incidence and disease pattern of young-onset CRC. The secondary objective is to explore the factors affecting overall survival in this population.

\section{Clinical management}

Patients who underwent elective colorectal surgery were managed according to the Enhanced Recovery After Surgery protocol. ${ }^{10}$ All cases were discussed in a multidisciplinary tumour board meeting where appropriate adjuvant therapy, surveillance interval and modality were recommended. Patients were followed up at 3-monthly intervals for the first 2 years and at 6-monthly intervals thereafter. Serial trending of serum carcinoembryonic antigen (CEA), interval imaging and colonoscopy were arranged in accordance with the National Comprehensive Cancer Network guidelines. ${ }^{11}$ Patients were followed up for a range of 2 to 9 years.

\section{Data collection}

Data on patients' demographics, presenting symptoms, tumour sites, staging and histology were collected. The nature of surgery, adjuvant treatment and postoperative outcomes were also evaluated. Staging of CRC was based on the $8^{\text {th }}$ edition of the American Joint Committee on Cancer Staging (AJCC-8). ${ }^{12}$ Tumours located proximal to the splenic flexure were classified as right-sided tumours while those located distal to the splenic flexure were defined as left-sided tumours. Post-operative outcomes were classified based on Clavien-Dindo classification. ${ }^{13}$ Information pertaining to length of stay, cancer recurrence and mortality was also recorded. Outcomes analysed include 5-year overall survival and disease-free survival. Data were retrieved from the hospital's electronic medical records and patients' operative notes.

Data analysis was performed using IBM SPSS, Version 22.0. Demographic, clinical, staging and operative data were presented with descriptive statistics. For categorical variables, counts and percentages were reported, while for continuous variables, mean and standard deviation were used. To evaluate the effect of prognostic factors on overall survival, univariate and multivariate Cox proportional hazards regression models were used. Variables with a $P$ value of $<0.1$ in a univariate Cox regression were considered as potential predictors to be included in the multivariate Cox model. Hazard ratios and their 95\% confidence intervals (CI) were calculated. Kaplan-Meier survival curves were used to illustrate overall and disease-free 5-year survival. $P$ values for the survival curves were determined from the Kaplan-Meier survival curves by using the log-rank test. All $P$ values of $<0.05$ were considered statistically significant. The study was approved by the National Healthcare Group's Domain Specific Research Board.

\section{Results}

Ninety-nine patients under 50 years of age with CRC were included in this study. The proportion of young-onset $\mathrm{CRC}$ in our institution ranged between $5.7 \%$ and $13.4 \%$ from 2011 to 2017 (Fig. 1). The mean age was $43.3(43.3 \pm 5.0)$ years; 62 patients $(62.6 \%)$ were male, and $37(37.4 \%)$ were female. The majority were Chinese 75 (75.8\%), followed by 14 (14.1\%) Malay, 7 (9.1\%) Indian and $3(3.0 \%)$ other ethnicities, closely mirroring the composition of the local population. The mean body mass index (BMI) was $23.8 \pm 3.92 \mathrm{~kg} / \mathrm{m}^{2}$. Smoking history was present in $17(17.2 \%)$ patients and alcohol use in 7 (7.1\%) (Table 1).

A total of $69(69.7 \%)$ patients had left-sided cancers while $30(30.3 \%)$ had right-sided ones. Of those with left-sided cancers, $30(30.3 \%)$ patients had rectal cancer (Table 1). Out of the 99 patients, 95 underwent surgery, 65 (68.4\%) underwent elective surgery, and 30 $(31.6 \%)$ underwent emergency surgery. The commonest presenting complaints for patients who underwent elective surgery were abdominal pain, per-rectal bleeding, as well as a change in bowel habits. For patients who required emergency surgery, $20(66.6 \%)$ presented with intestinal obstruction and $10(33.3 \%)$ had intestinal perforation (Table 1).

The mean haemoglobin level was $11.3 \pm 3.1 \mathrm{~g} / \mathrm{dL}$, and the mean preoperative CEA level was $28.7 \pm 81 \mathrm{~g} / \mathrm{ml}$. Thirty-seven patients $(41.6 \%)$ had CEA levels equal to or below $4 \mathrm{ng} / \mathrm{ml}$, while 52 patients $(58.4 \%)$ had CEA levels above $4 \mathrm{ng} / \mathrm{ml}$. Eighty-five $(85.9 \%)$ patients had high $\mathrm{T}$ staging (T3-T4) and 57 (57.3\%) were nodepositive $(\mathrm{N}+)$. Stage III CRC was found in $42(42.4 \%)$ of patients and Stage IV CRC in $20(20.2 \%)$ patients. The most frequent site of metastases in patients with stage IV CRC was in the liver $(20 / 20,100 \%)$. Out of these 20 patients $(60 \%), 9$ had isolated colorectal liver 
metastases, for which 6 underwent liver metastatectomy. The rest had additional metastases to other sites such as lungs, ovaries, peritoneum, brain, cervical spine and pelvic bone (Table 1).

With regard to cellular differentiation of the tumours, the majority $(87,87.9 \%)$ were moderately differentiated and $12(12.1 \%)$ were poorly differentiated in nature. Five had signet ring cells (5.1\%) in their histology, while 15 $(15.2 \%)$ had mucinous features. Microscopic vascular invasion (MVI) was present in $15(15.2 \%)$ patients; $3(3.0 \%)$ had perineural invasion (PNI), while 13 (13.1\%) had both MVI and PNI. The commonest molecular

Table 1. Demographics, disease factors and presenting complaints of young patients with colorectal cancer

\begin{tabular}{|c|c|}
\hline \multicolumn{2}{|l|}{ Comorbidities } \\
\hline Age (mean, standard deviation) & $43.3 \pm 5.0$ \\
\hline $\begin{array}{l}\text { Gender }(\mathrm{n}, \%) \\
\text { Male } \\
\text { Female }\end{array}$ & $\begin{array}{l}62(62.6) \\
37(37.4)\end{array}$ \\
\hline $\begin{array}{l}\text { Race }(\mathrm{n}, \%) \\
\text { Chinese } \\
\text { Malay } \\
\text { Indian } \\
\text { Others }\end{array}$ & $\begin{array}{c}75(75.8) \\
14(14.1) \\
7(9.1) \\
3(3)\end{array}$ \\
\hline BMI (mean, standard deviation) & $23.8 \pm 3.92$ \\
\hline Smoking (n, \%) & $17(17.2)$ \\
\hline Alcohol (n, \%) & $7(7.1)$ \\
\hline Diabetes mellitus (n, \%) & $13(13.1)$ \\
\hline Hypertension (n, \%) & $13(13.1)$ \\
\hline Hyperlipidemia (n, \%) & $7(7.1)$ \\
\hline Cardiac disease (n, \%) & $3(3)$ \\
\hline Factors & \\
\hline $\begin{array}{l}\text { Site of tumour (n, \%) } \\
\text { Right } \\
\text { Left } \\
\text { Rectum }\end{array}$ & $\begin{array}{l}30(30.3) \\
39(33.4) \\
30(30.3)\end{array}$ \\
\hline Pre-op haemoglobin (mean, standard deviation) & $11.3 \pm 3.1$ \\
\hline Pre-op CEA level (mean, standard deviation) & $28.7 \pm 81$ \\
\hline $\begin{array}{l}\text { Stage (n, \%) } \\
\text { I } \\
\text { II } \\
\text { III } \\
\text { IV }\end{array}$ & $\begin{array}{c}7(7.1) \\
30(30.3) \\
42(42.4) \\
20(20.2)\end{array}$ \\
\hline $\begin{array}{l}\text { T staging (n, \%) } \\
\text { T1 } \\
\text { T2 } \\
\text { T3 } \\
\text { T4 }\end{array}$ & $\begin{array}{c}2(2.0) \\
12(12.1) \\
49(49.5) \\
36(36.4)\end{array}$ \\
\hline
\end{tabular}

mutations were found in RAS gene $(13.1 \%)$ and microsatellite instability $(8.1 \%)$, followed by BRAF gene $(2.0 \%)$ and NRAS gene $(2.0 \%)$ (Table 1$)$.

Ninetye-five out of 99 patients underwent surgery. Laparoscopic surgery was performed in $36(37.9 \%)$ patients, open surgery in $59(62.1 \%)$ patients, and 3 $(3.2 \%)$ required permanent stomas due to complications of metastatic CRC. The remainder received palliation. The average length of stay overall was $9.7 \pm 12.2$ days. The average length of stay for patients who underwent elective surgery was $7.7 \pm 4.3$ days, compared to $14 \pm 20.4$ days in the emergency group $(P=0.042)$. Eleven $(11.1 \%)$

Table 1. Demographics, disease factors and presenting complaints of young patients with colorectal cancer (Cont'd)

\begin{tabular}{|c|c|}
\hline Factors & \\
\hline \multicolumn{2}{|l|}{$\mathrm{N}$ staging $(\mathrm{n}, \%)$} \\
\hline No & $42(42.4)$ \\
\hline N1 & $27(27.3)$ \\
\hline N2 & $30(30.3)$ \\
\hline Metastases (n, \%) & $20(20.2)$ \\
\hline \multicolumn{2}{|l|}{ Metastatic site (n, \% of metastases) } \\
\hline Liver only & $9(45.0)$ \\
\hline Mixed hepatic & $11(55.0)$ \\
\hline \multicolumn{2}{|l|}{ Cellular differentiation (n, \%) } \\
\hline Poor & $12(12.1)$ \\
\hline Moderate & $87(87.9)$ \\
\hline Signet ring histology (n, \%) & $5(5.1)$ \\
\hline Mucinous histology (n, n, \%) & $15(15.2)$ \\
\hline \multicolumn{2}{|l|}{ Microscopic description (\%) } \\
\hline MVI & $15(15.2)$ \\
\hline PNI & $3(3.0)$ \\
\hline Both & $13(13.1)$ \\
\hline \multicolumn{2}{|l|}{ Molecular mutations (n, \%) } \\
\hline RAS gene & $13(13.1)$ \\
\hline MSI gene & $8(8.1)$ \\
\hline BRAF gene & $2(2.0)$ \\
\hline NRAS gene & $2(2.0)$ \\
\hline \multicolumn{2}{|l|}{ Presentation complaints } \\
\hline \multicolumn{2}{|l|}{ Elective patients (n, \%) } \\
\hline Anaemia & $10(15.4)$ \\
\hline Change in bowel habits/tenesmus & $13(20.0)$ \\
\hline Per-rectal bleed & $21(32.3)$ \\
\hline Abdominal pain & $24(36.9)$ \\
\hline Constitutional symptoms & $9(13.8)$ \\
\hline \multicolumn{2}{|l|}{ Emergency patients (n, \%) } \\
\hline Obstruction & $20(66.6)$ \\
\hline Perforation & $10(33.3)$ \\
\hline
\end{tabular}

CEA: carcinoembryonic antigen, MSI: microsatellite instability, MVI: microscopic vascular invasion, PNI: perineural invasion 
patients had Clavien-Dindo grade III-IV postoperative complications, while 89 (93.7\%) underwent adjuvant therapy with curative intent. There were 14 (14.1\%) recurrences during the period of follow-up, and 22 $(22.4 \%)$ out of the 99 patients were deceased at the end of the study (Table 2).

The overall 5-year survival of patients with young-onset CRC in our study was $82.0 \%$. The 5-year stage-specific survival was $100 \%$ for stages I and II, followed by $83.3 \%$ for stage III and $45.0 \%$ for stage IV (Fig. 2). The overall 5 -year disease-free survival was $88.6 \%$ (Fig. 3).
Univariate analysis revealed that factors associated with poor overall survival were raised CEA levels (HR 7.74, CI 1.77-33.8), advanced overall stage (HR 7.55, CI 3.21-17.8), poor cellular differentiation of tumour (HR 12.2, CI 8.2-23.1), presence of signet ring histology (HR 9.6, CI 2.98-30.9), lympho-vascular invasion (HR 2.32, CI 1.47-3.63) and emergency surgery (HR 4.25, CI 1.06-1.75) (Table 2).

On multivariate analysis, only advanced overall stage (HR 6.1, CI 1.03-3.62) and presence of signet ring histology (HR 34.2, CI 2.24-5.23) were found to be independent predictors of poor overall survival (Table 3 ).

Table 2. Surgical factors and post-operative outcomes and univariate analysis of covariates affecting overall survival

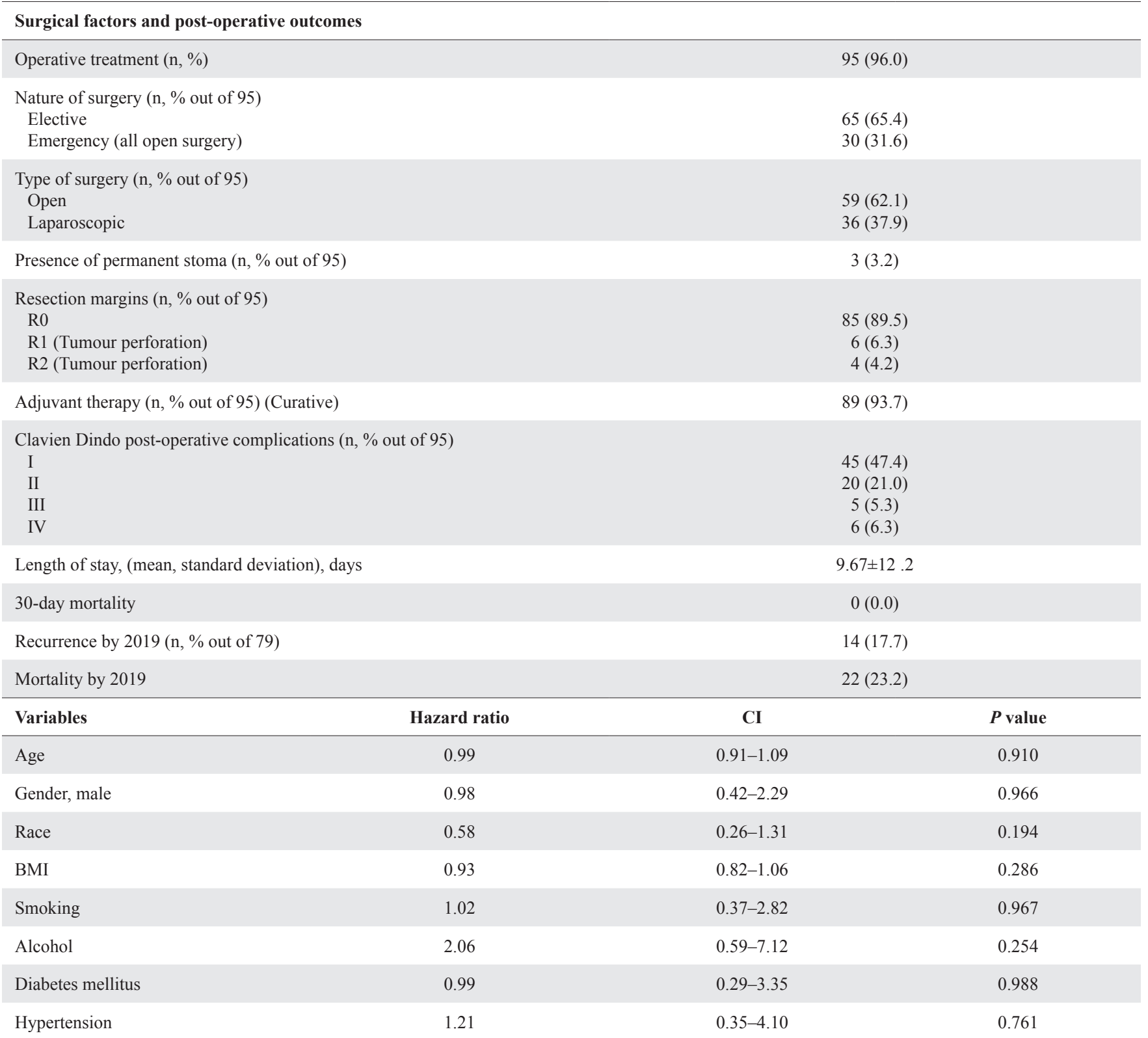


Table 2. Surgical factors and post-operative outcomes and univariate analysis of covariates affecting overall survival (Cont'd)

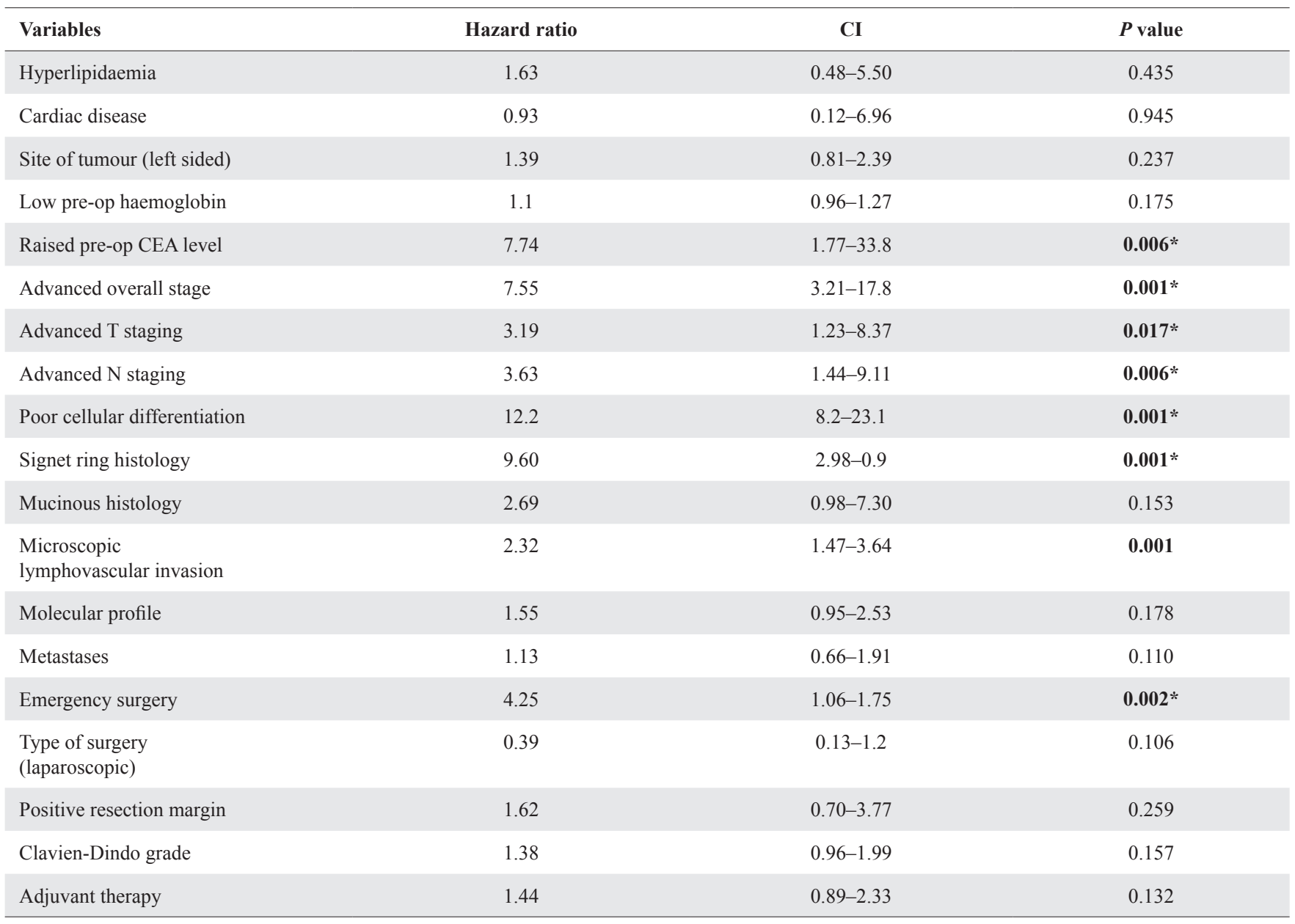

CEA: carcinoembryonic antigen

* Statistically significant, $P$ value $<0.05$

Table 3. Multivariate analysis of covariates affecting overall survival

\begin{tabular}{|c|c|c|c|}
\hline & Hazard ratio & $95 \% \mathrm{CI}$ & $P$ value \\
\hline Advanced overall stage & 6.10 & $1.03-3.62$ & $0.047 *$ \\
\hline Raised pre-op CEA level & 1.01 & $0.99-1.02$ & 0.344 \\
\hline Emergency surgery & 3.13 & $0.14-7.00$ & 0.472 \\
\hline Poor cellular differentiation & 0.21 & $0.23-2.01$ & 0.177 \\
\hline Signet ring histology & 34.2 & $2.24-5.23$ & $0.011^{*}$ \\
\hline $\begin{array}{l}\text { Microscopic } \\
\text { lymphovascular invasion }\end{array}$ & 1.00 & $0.35-2.96$ & 0.996 \\
\hline
\end{tabular}

CEA: carcinoembryonic antigen

*Statistically significant, $P$ value $<0.05$ 


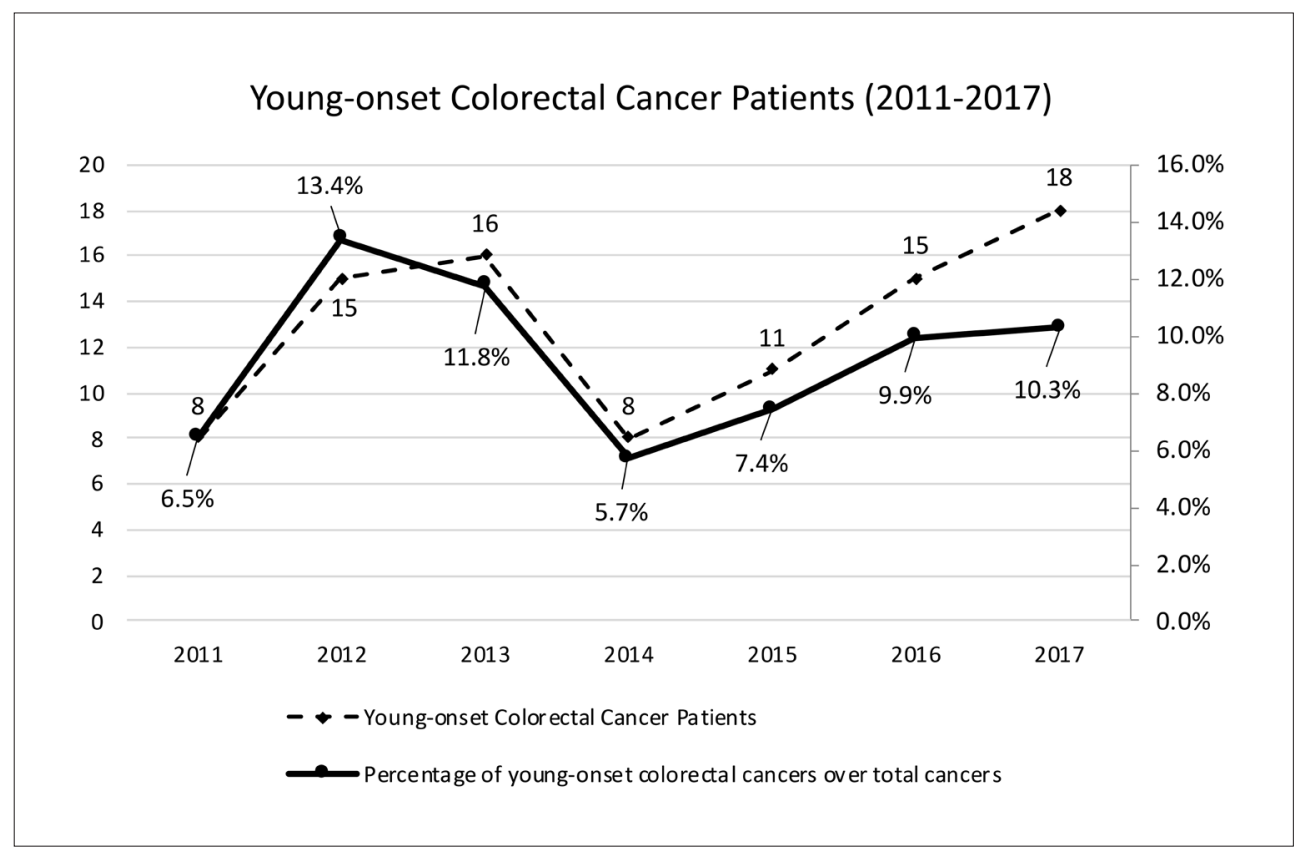

Fig. 1. Trend of young-onset colorectal cancer in Khoo Teck Puat Hospital

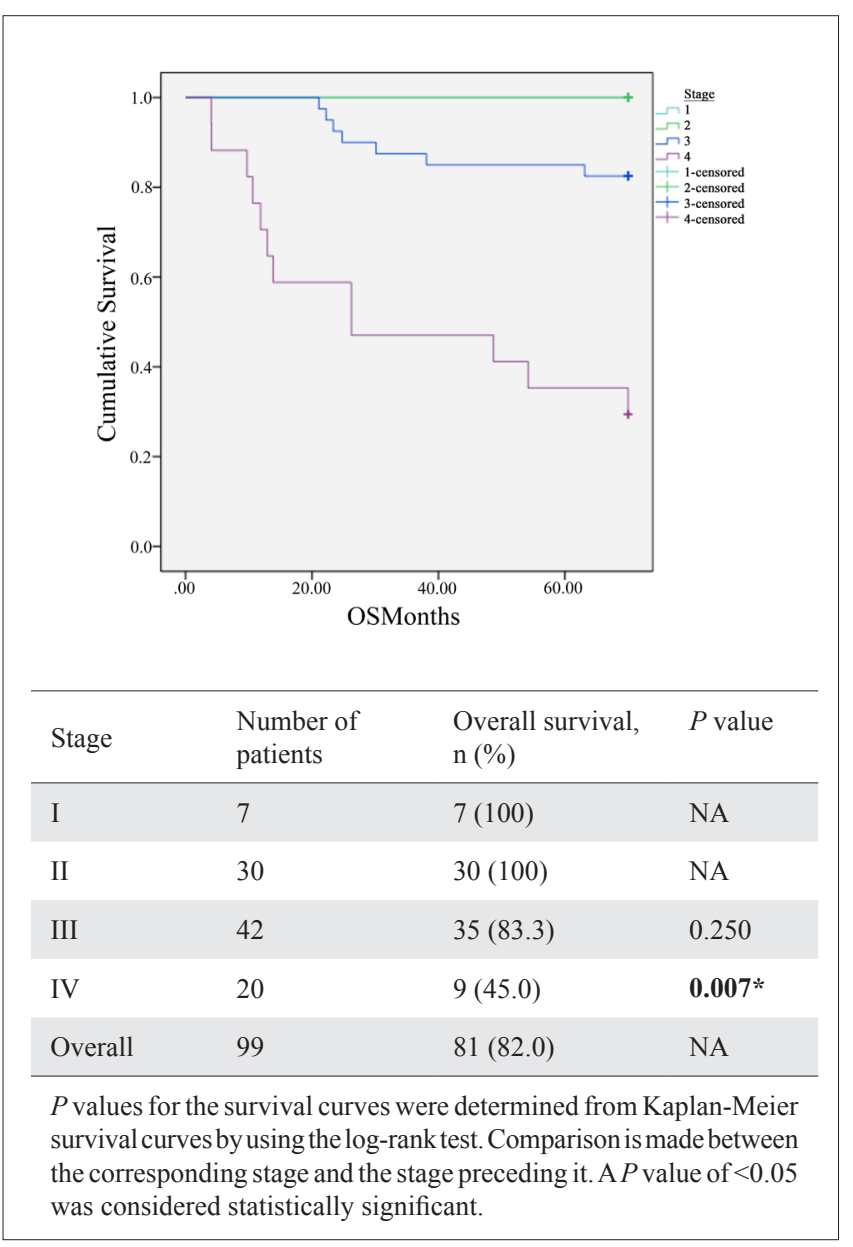

Fig. 2. Overall 5-year survival of young-onset colorectal cancer patients

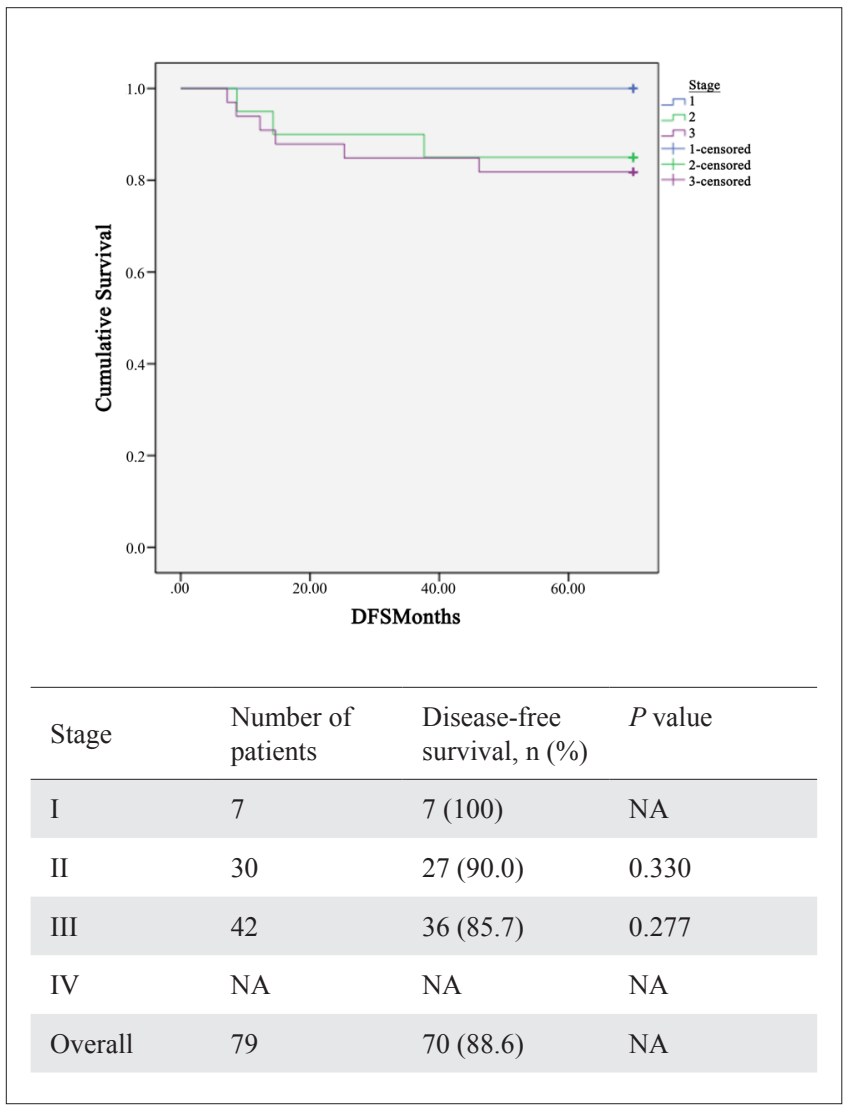

Fig. 3. 5-year disease-free survival of young-onset colorectal cancer patients. 


\section{Discussion}

\section{Clinical presentation}

The rising trend of young-onset CRC in the past decade has been reported internationally. ${ }^{14,15}$ According to data from the Singapore Cancer Registry, the incidence rate by primary site (colorectal) below the age of 50 years has been on the rise as well. The incidence rate in each 5-year period: 2003-2007 was 103.1\%, 20082012 was $109.5 \%$, and 2013-2017 was $119.2 \%$, respectively. ${ }^{16}$ In our institution, the proportion of young-onset CRC ranged from $5.7 \%$ to $13.4 \%$ during the period 2011 to 2017. Of the 99 young patients diagnosed with CRC in our study, none had prior colonoscopy or sigmoidoscopy. The proportion of stage 4 and emergency cases in our study were comparably higher than studies in adults above age 50 years. ${ }^{17,18}$ These findings suggest that young patients with CRC in our institution were often diagnosed late. Up to $31.6 \%$ of them required emergency open surgeries due to tumour crises. Perforated tumours accounted for $10.5 \%$ of operative cases with $\mathrm{R} 1$ and $\mathrm{R} 2$ resection margins. Studies have shown that tumour perforation is a strong predictor of locoregional failure.

\section{Tumour biology}

Besides delayed detection of CRC, tumour biology of young patients with CRC may play a part in determining overall survival. Mucinous adenocarcinoma (MAC) accounts for $10-15 \%$ and signet ring cell carcinoma (SRC) accounts for $0.1-2.4 \%$ of CRC cases in the general population. ${ }^{19} \mathrm{~A}$ study by Ahnen et al. reported that young-onset CRC more frequently exhibit SRC and MAC than late onset CRC $(18 \%$ versus $12.6 \%, P<$ $0.001) .{ }^{20}$ However, the aetiology of these histological differences remains unknown. Our study had similar proportions of young patients with SRC (5.1\%) and MAC $(15.2 \%)$. The pathological feature of SRC is the presence of single tumour cells with intracytoplasmic mucin that displaces the nuclei, while MAC is characterised by an abundance of extracellular mucin pools. Both MAC and SRC are known to affect younger patients, are associated with advanced presentations, and undergo more frequent lymph node or peritoneal metastases. Although the poor prognosis of SRC has been widely recognised, the prognosis of MAC remains controversial. Some studies did not find MAC an independent predictor for poor prognosis in CRC patients after multivariate analysis, leading to the hypothesis that the negative prognostic effect of MAC on survival could be attributed by the advanced stage of presentation instead. Comparatively, the presence of SRC but not MAC was an independent predictor for poor prognosis in our study.

\section{Metastatic disease}

One-fifth of young patients had evidence of metastases at the time of presentation, of whom $11 \%$ had synchronous isolated liver metastases. Complete hepatic metastatectomy is the only treatment modality for curative intent. It confers an increase in 5-year survival rate of $30 \%$ to $65 \%$. Resection of primary CRC and hepatic metastasis can be performed simultaneously or in a 2-stage approach, with comparable long-term outcomes..$^{21,22}$ In patients with concerns of limited future liver remnant, options for treatment include portal vein embolisation, associating liver partition, and portal vein ligation for staged hepatectomy or a combination of ablation and resection of liver metastases. The role of liver transplantation in highly selected patients with colorectal liver metastases will require validation from large-scale clinical trials. Neoadjuvant or adjuvant chemotherapy, targeted biological agents and locoregional therapies (e.g. thermal ablation or intra-arterial chemo- or radio-embolisation) may further improve the results.

\section{Five-year survival data}

The overall 5-year survival in our study population of young patients was $82 \%$ compared to the general population of $65 \%(\mathrm{AJCC} 8)^{12}$. The current literature is ambivalent with regard to the prognosis of young-onset as compared to late-onset CRC. Some studies described a more favourable prognosis in younger patients due to minimal comorbidities and higher receipt of surgery or chemotherapy, ${ }^{23}$ while others showed worse prognosis attributed to advanced stage at presentation and aggressive tumour biology. However, when matched by tumour stage, survival rates appeared to be better in young adults compared with older adults. ${ }^{24}$ Similar to a recent paper by Ulanja et al., ${ }^{25}$ our study found that young patients tend to present with metastatic CRC $(20.2 \%)$ but their 5-year overall survival remained favourable. All young patients with Stage I and II were alive 5 years after their diagnosis. The 5 -year survival rate of $45 \%$ for Stage 4 disease was superior to that reported by Ulanja et al. of $18 \%{ }^{25}$ This may be attributed to liver metastatectomy being performed in 
the majority (6 out of 9) of patients with isolated colorectal liver metastases, and the high proportion of patients $(93.7 \%)$ who underwent adjuvant chemotherapy in our study.

\section{Strategies to increase early detection rates}

In the past, routine CRC screening in young adults below the age of 50 years was not considered costeffective. However, in light of the increase in incidence of young-onset CRC, there is a growing interest in preventive and early detection strategies. In 2018, the American Cancer Society revised its recommendation for colonoscopy by lowering the screening age from 50 to 45 years old. ${ }^{26}$ Currently, our local screening guidelines have not encompassed patients below 50 years of age. A myriad of strategies has been explored to increase early detection rates. Firstly, physicians can be encouraged to have a high index of suspicion in young adults presenting with red flag symptoms, and consider early referral for diagnostic evaluation. This is especially since more than half of the patients presented with symptoms such as a change in bowel habits and per-rectal bleeding. Secondly, a detailed history to identify patients at increased risk of developing CRC should be taken. This includes those with personal or family history of advanced adenomas or CRC, personal history of inflammatory bowel disease or genetic polyposis syndromes..$^{27}$ Thirdly, there is ongoing debate regarding the type of screening modality in the young such as flexible sigmoidoscopy versus standard colonoscopy. ${ }^{28}$

Based on the anatomical distribution of tumours in the young-onset CRC in our study, $69.7 \%$ of these tumours were left-sided and within the range of a flexible sigmoidoscopy. Comparatively, international studies on young-onset CRC, excluding hereditary cancers, have shown similar left-sided predominance $(78.6 \%-83 \%))^{14,26}$ It has been well established that right-sided CRC is predominantly characterised by microsatellite instability, and is associated with the commonest form of hereditary CRC known as the Lynch syndrome. The mean age of presentation in patients with Lynch syndrome is 44 years, which is approximately 20 years earlier than CRC cases. However, these cases were excluded from our study. On the other hand, left-sided CRC is characterised by chromosomal instability and development via the multi-step genetic model for colorectal cancer. This is associated mainly with sporadic tumours.

To the young individual, flexible sigmoidoscopy may be more desirable in terms of doing away with bowel preparation, slightly lower risk of perforation than colonoscopy, as well as less discomfort and cost. However, without a colonoscopy, $30 \%$ of right-sided tumours, not including hereditary cancers in our study may not have been detected or prevented.

\section{Limitations}

To our knowledge, this study is the first in Singapore to review the 5-year survival rates for young individuals with colorectal cancer. There are several limitations in our study. Firstly, the sample size was small as our patients were enrolled from a single institution. It would be useful to conduct a nationwide study to explore clinical trends, as well as assess the benefits of early screening and the appropriate modality to do so. ${ }^{29}$ Secondly, our study did not include a control group of patients above the age of 50 with CRC. However, data on the latter have been widely published in the literature. ${ }^{30,31}$ Lastly, the difference in follow-up period for patients diagnosed at varying time points may have introduced bias in overall outcomes.

\section{Conclusion}

The rise in incidence of young patients $(<50$ years) with $\mathrm{CRC}$ and their tendency for late presentation call for the need to heighten awareness and develop strategies for early detection. They belong to a key demographic in which screening and preventive efforts are currently not available. Comprehensive clinical assessment with a high index of suspicion for symptomatic patients is necessary. Further research is warranted to determine if lowering of screening age or offering flexible sigmoidoscopy screening in this population will be beneficial.

\section{REFERENCES}

1. Mauri G, Sartore-Bianchi A, Russo AG, et al. Early-onset colorectal cancer in young individuals. Mol Oncol 2019;13:109-31.

2. Zauber AG. The impact of screening on colorectal cancer mortality and incidence: has it really made a difference?. Dig Dis Sci 2015;60: 681-91.

3. Herbert A, Lyratzopoulos G, Whelan J, et al. Diagnostic timelines in adolescents and young adults with cancer: a multicentre, crosssectional analysis of the BRIGHTLIGHT cohort. Lancet Child Adolesc Health 2018;2:180-90.

4. Crosbie AB, Roche LM, Johnson LM, et al. Trends in colorectal cancer incidence among younger adults-Disparities by age, sex, race, ethnicity, and subsite. Cancer Med 2018;7:4077-86.

5. Pita-Fernández S, González-Sáez L, López-Calviño B, et al. Effect of diagnostic delay on survival in patients with colorectal cancer: a retrospective cohort study. BMC Cancer 2016;16:664. Murchie P, Raja EA, Brewster DH, et al. Time from first presentation in primary care to treatment of symptomatic colorectal cancer: effect on disease stage and survival. Br J Cancer 2014;111:461-9.

6. Miedema BB, Easley J, Hamilton R. Young adults' experiences with cancer: comments from patients and survivors. Can Fam Physician 2006;52:1446-7. 
7. Chouhan H, Ferrandon S, DeVecchio J, et al. A Changing Spectrum of Colorectal Cancer Biology With Age: Implications for the Young Patient. Dis Colon Rectum 2019;62:21-6.

8. Iyer P, Wong $\mathrm{K}$, Lieu $\mathrm{CH}$, et al. Clinical and molecular characteristics of younger versus older patients with colorectal cancer. J Clin Oncol 2018; 36:630.

9. Carmichael JC, Keller DS, Baldini G, et al. Clinical Practice Guidelines for Enhanced Recovery After Colon and Rectal Surgery From the American Society of Colon and Rectal Surgeons and Society of American Gastrointestinal and Endoscopic Surgeons. Dis Colon Rectum 2017;60:761-84

10. Benson AB, Venook AP, Al-Hawary MM, et al. NCCN Guidelines Insights: Colon Cancer, Version 2.2018. Journal of the National Comprehensive Cancer Network J Natl Compr Canc Netw 2018;16:359-69.

11. Amin MB, Edge S, Greene F, et al. (Eds.). AJCC Cancer Staging Manual (8th edition). Springer International Publishing, 2017.

12. Dindo D, Demartines N, Clavien PA. Classification of surgical complications: a new proposal with evaluation in a cohort of 6336 patients and results of a survey. Ann Surg 2004;240:205-13.

13. Kasi PM, Shahjehan F, Cochuyt JJ, et al. Rising proportion of young individuals with rectal and colon cancer. Clin Colorectal Cancer 2019;18:e87-e95.

14. Connell LC, Mota JM, Braghiroli MI, et al. The Rising Incidence of Younger Patients With Colorectal Cancer: Questions About Screening, Biology, and Treatment. Curr Treat Options Oncol 2017; 18-23.

15. Singapore Cancer Registry - Health Promotion Board. Singapore Cancer Registry 50th Anniversary Monograph - Appendices. National Registry of Diseases Office. 2019. Available at: https://www.nrdo.gov. sg/publications/cancer. Accessed on 13 September 2020

16. Moghadamyeghaneh $\mathrm{Z}$, Alizadeh RF, Phelan M, et al. Trends in colorectal cancer admissions and stage at presentation: impact of screening. Surg Endosc 2016;30:3604-10.

17. Taylor MC, Pounder D, Ali-Ridha NH, et al. Prognostic factors in colorectal carcinoma of young adults. Can J Surg 1988;31:150-3.

18. Quesada-Soto P, Landaverde D, Ramos-Esquivel A. Liver Metastasectomy and Systemic Therapy Improve Overall Survival
Compared With Surgery Alone After Curative Liver Resection of Colorectal Metastases in a Developing Country (Costa Rica). J Glob Oncol 2016;3:31-6.

19. Ahnen DJ, Wade SW, Jones WF, et al. The increasing incidence of young-onset colorectal cancer: a call to action. Mayo Clin Proc 2014;89:216-24

20. O'Connell JB, Maggard MA, Livingston EH, et al. Colorectal cancer in the young. Am J Surg 2004;187:343-8.

21. Tan EK, Ooi LL. Colorectal cancer liver metastases - understanding the differences in the management of synchronous and metachronous disease. Ann Acad Med Singap 2010;39:715-9.

22. Singapore Cancer Network (SCAN) Colorectal Cancer Systemic Therapy Workgroup. Singapore Cancer Network (SCAN) Guidelines for Systemic Therapy of Colorectal Cancer. Ann Acad Med Singap 2015;44:379-87.

23. Quah HM, Joseph R, Schrag D, et al. Young age influences treatment but not outcome of colon cancer. Ann Surg Oncol 2007;14:2759-65.

24. Ulanja MB, Beutler BD, Rishi M, et al. Colorectal Cancer Presentation and Survival in Young Individuals: A Retrospective Cohort Study. Cancers (Basel) 2018;10:472

25. The American Cancer Society. American Cancer Society Guideline for Colorectal Cancer Screening. Feb 2018. Available at: https:/www.cancer.org/health-care-professionals/american-cancersociety-prevention-early-detection-guidelines/colorectal-cancerscreening-guidelines.html. Accessed on 13 September 2020.

26. Yong $\mathrm{CK}, \mathrm{Ng} \mathrm{BK}$. Large bowel cancer in the young adult. Ann Acad Med Singap 1990;19:385-8.

27. Segev L, Kalady MF, Church JM. Left-Sided Dominance of Early-Onset Colorectal Cancers: A Rationale for Screening Flexible Sigmoidoscopy in the Young. Dis Colon Rectum 2018;6:897-902.

28. Tan MH. World Cancer Day. Ann Acad Med Singap 2018;47(3):88-9.

29. Mistry SA, Madala H, Chacko C, et al. Colon cancer: Characteristics and survival rates in young versus old patients. Journal of Clinical Oncology 2014;32:3585.

30. Li Q, Cai G, Li D, et al. Better long-term survival in young patients with non-metastatic colorectal cancer after surgery, an analysis of 69,835 patients in SEER database. PLoS One. 2014;9:e93756. 